\title{
Brachial plexus injury as an unusual complication of coronary artery bypass graft surgery
}

\author{
A Y Chong, C E Clarke, W R Dimitri, G Y H Lip
}

Postgrad Med J 2003;79:84-86

Brachial plexus injury is an unusual and under-recognised complication of coronary artery bypass grafting especially when internal mammary artery harvesting takes place. It is believed to be due to sternal retraction resulting in compression of the brachial plexus. Although the majority of cases are transient, there are cases where the injury is permanent and may have severe implications as illustrated in the accompanying case history.

See end of article for authors' affiliations

Correspondence to: Professor G Y H Lip, University Department of Medicine, City Hospital, Birmingham B18 7QH, UK; g.y.h.lip@bham.ac.uk

Submitted 23 July 2002 Accepted

25 November 2002
N eurological complications after coronary artery bypass grafting (CABG) are common (see the illustrative case history in box 1). In a study of 312 patients by Shaw et al, $61 \%$ of patients showed evidence of neurological complications with detailed investigation, although serious morbidity was rare with "severe disability" (defined as incapable of leading an independent existence) only occurring in four patients $(1.3 \%)$. The commonest neurological complications were primitive reflexes-that is, development of palmomental reflex, pout reflex or grasp reflex $(39 \%)$, ophthalmological abnormalities $(25 \%)$, and disorders of the peripheral nervous system (12\%). Seven percent (21 patients) of the total number of patients had brachial plexopathy. Death as a result of hypoxic brain injury accounted for $0.3 \%$, whereas definite stroke accounted for $5 \%$ of neurological complications. ${ }^{1}$ Mild cognitive impairment and memory loss are also frequent complications of cardiac surgery but these tend to be subtle. There is an extensive literature on central nervous complication which is beyond the scope of this article.

Only brachial plexus injury will be discussed in detail in this article. Other nerves that are not infrequently injured during $C A B G$ include the phrenic, ${ }^{2}$ sympathetic, ulnar, and radial nerves. ${ }^{3-7}$ More rarely, injury to the recurrent laryngeal nerve may also occur. ${ }^{8}$ While phrenic nerve palsy is relatively harmless if unilateral, bilateral phrenic nerve palsy has significant impact on the patient's recovery and also morbidity status postoperatively. ${ }^{9}$ This is particularly so if the patient also suffers from respiratory disorders whereby tidal volumes are already reduced such as chronic obstructive airways disease. ${ }^{10}$ Phrenic nerve injury is thought to be due to hypothermia induced by ice slush during cardioplegia and hence may be preventable by phrenic nerve insulation intraoperatively ${ }^{6}$; injury can also be avoided by warm cardioplegia. ${ }^{11}{ }^{12}$ Injury to the sympathetic nerve resulting in Horner's syn- drome is a further recognised complication of CABG ${ }^{13}{ }^{14}$ Moreover, radial nerve injury may also be caused by sternal retraction during internal mammary artery harvesting. ${ }^{15} 16$

\section{INCIDENCE OF BRACHIAL PLEXOPATHY}

Brachial plexus injury after CABG is not an infrequent complication but it is under-diagnosed and under-reported as it is often transient. ${ }^{13-19}$ The risk of brachial plexus injury in this context has been reported to be between $5.5 \%$ and $10 \%$ (table 1). ${ }^{1320}$ It is thought that the injury is a consequence of the sternal split and retraction transmitting compressive pressure to the nerve roots. Brachial plexus injury is also more common if internal mammary artery preparation is required. In a prospective study of 1000 consecutive patients, Vahl et al reported that CABG was associated with a $1 \%$ risk of brachial plexus injury if no internal mammary artery preparation was involved, with the risk rising to over $10 \%$ otherwise. This prevalence occurs despite preventive measures used by the investigators to minimise this particular complication such as using a lower position and least possible opening with the sternal retractor. ${ }^{13}$ Bearing in mind that the use of internal mammary arteries as conduits in CABG is increasing, one can only surmise that this complication will become more common and patients will need to be made aware at the time consent is obtained, even more so if their livelihood depends on it. More importantly, steps need to be taken to minimise this complication.

\section{MECHANISMS OF BRACHIAL PLEXOPATHY}

Several mechanisms have been proposed as the cause of brachial plexus injury during CABG. These include hyperabduction of the arms, direct trauma during needle catheterisation of the internal jugular vein, and traction and compression during sternal retraction. ${ }^{19}{ }^{20}$ During harvesting of the internal mammary artery, asymmetrical traction of the sternal halves appears to be associated with a higher risk of brachial plexopathy. ${ }^{18}$ Other factors associated with a higher risk of brachial plexopathy are diabetes mellitus and hypothermia during surgery, with diabetes also being associated with a longer duration of disability. ${ }^{1720}$ The predisposition of the lower roots ( $\mathrm{C} 7-\mathrm{Tl})$ to be injured in comparison with the upper roots lends support to the theory

Abbreviations: $C A B G$; coronary artery bypass grafting; SEP; somatosensory evoked potential 


\section{Box 1: Illustrative case history}

A 61 year old man first presented with an inferior myocardial infarction in 1998, which was treated with streptokinase. He had a total cholesterol level of $5.2 \mathrm{mmol} / \mathrm{l}$ on admission. There was no history of hypertension, diabetes, or prior coronary artery disease. He had a peak creatine kinase rise of $3259 \mathrm{IU} / \mathrm{l}$ and was discharged from hospital a week later without complication. An exercise tolerance test performed a month later was clinically positive with less than $1 \mathrm{~mm}$ ST depression in the inferolateral leads. Coronary angiography showed a virtually normal left coronary system but an occluded proximal right coronary artery, which filled retrogradely from the left coronary artery. The left ventricular function was good. An elective percutaneous transluminal coronary angioplasty of the right coronary artery was unsuccessful and he was therefore referred to the cardiothoracic surgeon for $C A B G$ to his distal right coronary artery.

Nine months after his myocardial infarction, he underwent a right internal mammary artery bypass graft to his distal right coronary artery, off pump. His postoperative course was complicated by a chest infection on the third day which responded to oral antibiotics. He complained of left arm weakness in his early postoperative course. On review two months later, he was doing very well from a cardiovascular aspect; but his left arm weakness persisted and marked muscle wasting was noted in the small muscles of his left hand and medial aspect of his left forearm. The distribution of muscle weakness was clinically consistent with either ulnar neuropathy or brachial plexopathy. There was no sensory loss detected clinically. He was no longer able to work as a joiner.

Nerve conduction studies were consistent with a proximal high brachial plexus lesion located at the root level of C7, C8, and T1 on the left. Profuse denervation was noted in the left first dorsal interosseous, abductor pollicis brevis, and patchy denervation in the long extensors of the forearm and triceps muscles. Although there was no sensory loss detected clinically, neurophysiology revealed at least a $50 \%$ reduction in the size of the sensory nerve action potential in the corresponding dermatomes. Subsequent follow up at eight and 14 months after surgery showed no improvement in his clinical condition.

that sternal retraction is the cause, as the lower roots would be compressed most in the retroclavicular space.

The utilisation of somatosensory evoked potential (SEP) monitoring of bilateral ulnar and median nerves intraoperatively may be used to predict peripheral nerve injury during cardiac surgery. In a study involving 30 patients undergoing cardiac surgery, Hickey et al reported a 13\% incidence of SEP changes during internal jugular venous cannulation. However, the changes were intermittent and transient, and none of the patients eventually suffered any neurological deficit. Significant SEP changes were observed in $70 \%$ of patients with the use of the Canadian or Favoloro retractors but the majority reverted to normal intraoperatively. In five patients, however, the changes persisted to the end of the operation and these five patients subsequently demonstrated neurological deficits. ${ }^{21}$ Another study by Jellish et al showed large decreases in SEP on insertion of Rultract and Pittman retractors in 85\% and $68.75 \%$ of patients respectively. Although this improved after removal, the amplitudes did not return to baseline. Only mild decreases were noted in their control group where Cooley retractors were used in patients not undergoing internal mammary artery harvesting. ${ }^{22}$ They concluded that SEP was a sensitive marker to detect nerve injury.

In a further study of 36 patients by Baisden et al, the removal of the uppermost blades of the conventional Ankeney retractor was associated with a reduced incidence of occult rib fractures (evident on bone scans but not chest radiographs) overall. In particular, occult posterior first rib fractures were found to be associated with brachial plexus injury. ${ }^{23}$ These findings would be consistent with the notion that increased traction and compression by sternal retractors have a role in brachial plexus injury. However, the number of patients in the published studies were relatively small. With the advent of thoracoscopic harvesting of the internal mammary artery and minimally invasive CABG (that is, minithoracotomy), sternal retraction may be minimised ${ }^{24-28}$ and perhaps brachial plexus injury reduced. Totally endoscopic CABG would be something to look forward to in the future.

Finally, arm positioning during internal mammary artery harvest may also influence brachial plexus injury. Indeed, some suggest that the "hands-up" position may actually reduce the occurrence compared with the usual "arms-at-theside" position. It is hypothesised that the "hands-up" position may in fact reduce brachial plexus stress during asymmetric sternal retraction. However, in a study of 80 patients, Jellish et al showed that the "hands-up" position offered little protection against brachial plexus stress based on SEP. An interesting finding in that study was that although patients in both groups suffered with brachial plexus injury, those who also show ulnar nerve problems were in the "arms-at-theside" group only. This suggests that the "arms-at-the-side" position may also predispose to ulnar nerve compression but not the "hands-up" position. ${ }^{29}$

\section{BRACHIAL PLEXOPATHY OR ULNAR NEUROPATHY?}

It is important to distinguish brachial plexopathy from ulnar neuropathy, the main differential diagnosis, as the underlying mechanisms appear to be different as well as the prognosis. In the study by Vahl et al, eight of 27 patients who developed brachial plexus injury had persistent symptoms three months

Table 1 Studies of brachial plexus injury and CABG

\begin{tabular}{|c|c|c|}
\hline Investigators & Study & Comment \\
\hline Vahl et al ${ }^{13}$ & $\begin{array}{l}n=1000 \text {; prospective study of } 1000 \\
\text { consecutive patients }\end{array}$ & $\begin{array}{l}\text { Brachial plexus injury occurred in }<1 \% \text { of } \\
\text { patients not requiring internal mammary } \\
\text { artery preparation with the risk rising to } \\
10.6 \% \text { if internal mammary artery } \\
\text { preparation was required }\end{array}$ \\
\hline Shaw et al & $\mathrm{n}=312 ;$ prospective study & $\begin{array}{l}\text { Brachial plexus damage occurred in } 6.7 \% \text { of } \\
\text { patients }\end{array}$ \\
\hline Lederman et $a^{20}$ & $\mathrm{n}=421$; Cleveland clinic study & $\begin{array}{l}\text { Brachial plexus injury occurred in } 5.5 \% \text { of } \\
\text { patients undergoing } C A B G\end{array}$ \\
\hline Baisden et $a^{23}$ & $\mathrm{n}=36$ (small patient numbers) & $\begin{array}{l}\text { Removal of the uppermost blades of the } \\
\text { Ankeney retractor reduced risk of posterior } \\
1 \text { st rib fractures and brachial plexus injury }\end{array}$ \\
\hline
\end{tabular}


Table 2 Mechanism and prevention of nerve injury

\begin{tabular}{lll}
\hline Nerve injury & Proposed mechanism & Prevention \\
\hline $\begin{array}{l}\text { Brachial } \\
\text { plexopathy }\end{array}$ & $\begin{array}{l}\text { Traction and compression } \\
\text { of nerves during sternal } \\
\text { retraction (internal } \\
\text { jugular venous } \\
\text { cannulation) }\end{array}$ & $\begin{array}{l}\text { retraction and at a lower } \\
\text { position; may be reduced } \\
\text { by thoracoscopic } \\
\text { harvesting of the internal } \\
\text { mammary artery }\end{array}$ \\
$\begin{array}{l}\text { Ulnar } \\
\text { neuropathy }\end{array}$ & $\begin{array}{l}\text { Arm position resulting in } \\
\text { compression of the ulnar } \\
\text { nerve }\end{array}$ & $\begin{array}{l}\text { Avoidance of local } \\
\text { compression either by } \\
\text { arm position or other } \\
\text { means of protection of } \\
\text { the humeral groove } \\
\text { Phrenic nerve insulation } \\
\text { intraoperatively and } \\
\text { warm cardioplegia }\end{array}$ \\
\hline $\begin{array}{l}\text { Phrenic nerve } \\
\text { palsy }\end{array}$ & $\begin{array}{l}\text { Hypothermia from ice } \\
\text { slush for cardioplegia } \\
\text { (perhaps also stretching) }\end{array}$ &
\end{tabular}

postoperatively. ${ }^{13}$ The cause of postoperative ulnar nerve palsy is not one that is readily identifiable but is thought to be a result of local nerve compression/trauma in the posterior condylar groove. This could be due to malposition of the arm, either intraoperatively or postoperatively when the patient is immobile. It has also been suggested that it may be due to prolonged ischaemia of the upper limb during CABG. ${ }^{30}$ Its prognosis tends to be less favourable than brachial plexus injury, ${ }^{31}$ although these data come from non-cardiac surgery. ${ }^{32-34}$ In one prospective study of 335 patients undergoing median sternotomy for cardiac surgery by Tomlinson et al, 16 patients developed brachial plexus injury with only one patient still symptomatic at the time of discharge. However, they placed all their patients in the "hands-up" position and were careful with sternal retraction. ${ }^{35}$ This may have prevented more significant damage, thereby producing a more favourable outcome. Utilisation of nerve conduction studies allows differentiation between ulnar neuropathy and brachial plexus injury quite readily. Accurate diagnosis allows steps to be taken to reduce these complications which may not be inconsequential as illustrated in this case. Further investigation is required on the effects of reduction of sternal retraction force on SEP and if this will actually prevent brachial plexopathy (table 2).

\section{CONCLUSION}

It is important to inform patients of the potential neurological complications that may occur after CABG. Care should be taken to minimise the risk of these complications during surgery and, to that end, the mechanism by which they occur requires further investigation. This is particularly appropriate with the increasing use of internal mammary artery conduits which is associated with a higher incidence of brachial plexus injury. More recently, however, the introduction of thoracoscopic harvesting of the internal mammary artery and minimally invasive CABG obviates the need for excessive sternal retraction ${ }^{24-28}$ and hence, may prevent brachial plexus injury.

\section{Authors' affiliations}

A Y Chong, G Y H Lip, University Department of Medicine, City Hospital, Birmingham

C E Clarke, University Department of Neurology, City Hospital, Birmingham

W R Dimitri, Department of Cardiothoracic Surgery, Walsgrave Hospital, Coventry

\section{REFERENCES}

I Shaw PJ, Bates D, Cartlidge NE, et al. Early neurological complications of coronary artery bypass surgery. BM 1985;291:1384-7.

2 Ando $M$, Endo $M$, Nishida $H$, et al. [Phrenic nerve injury following coronary artery bypass surgery: its clinical implication and management.] Rinsho Kyobu Geka 1994;14:501-5.
3 Cruz-Martinez A, Armijo A, Fermoso A, et al. Phrenic nerve conduction study in demyelinating neuropathies and open-heart surgery. Clin Neurophysiol 2000:111:821-5.

4 DeVita MA, Robinson LR, Rehder J, et al. Incidence and natural history of phrenic neuropathy occurring during open heart surgery. Chest 1993; 103:850-6

5 Katz MG, Katz R, Schachner A, et al. Phrenic nerve injury after coronary artery bypass grafting: will it go away? Ann Thorac Surg 1998;65:32-5

6 Laub GW, Muralidharan S, Chen C, et al. Phrenic nerve injury. A prospective study. Chest 1991;100:376-9.

7 Rousou JA, Parker T, Engelman RM, et al. Phrenic nerve paresis associated with the use of iced slush and the cooling jacket for topical hypothermia. J Thorac Cardiovasc Surg 1985;89:921-5.

8 Phillips TG, Green GE. Left recurrent laryngeal nerve injury following internal mammary artery bypass. Ann Thorac Surg 1987;43:440.

9 Werner RA, Geiringer SR. Bilateral phrenic nerve palsy associated with open-heart surgery. Arch Phys Med Rehabil 1990;71:1000-2.

10 Cohen AJ, Katz MG, Katz R, et al. Phrenic nerve injury after coronary artery grafting: is it always benign? Ann Thorac Surg 1997;64:148-53.

11 Maccherini M, Davoli G, Sani G, et al. Warm heart surgery eliminates diaphragmatic paralysis. J Card Surg 1995;10:257-61.

12 Tolis GA, Astras G, Sfyras N, et al. Experience with warm blood cardioplegia in 480 patients. Cardiovasc Surg 1995:3:175-80.

13 Vahl CF, Carl I, Muller-Vahl H, et al. Brachial plexus injury after cardiac surgery. The role of internal mammary artery preparation: a prospective study on 1000 consecutive patients. J Thorac Cardiovasc Surg 1991:102:724-9.

14 Barbut D, Gold JP, Heinemann MH, et al. Horner's syndrome after coronary artery bypass surgery. Neurology 1996;46:181-4.

15 Fernandez dC, Duarte J, Lozano A, et al. [Radial nerve injury caused by external compression during the dissection of the internal mammary artery in coronary surgery.] Rev Esp Anestesiol Reanim 1992:39:371-3.

16 Guzman F, Naik S, Weldon OG, et al. Transient radial nerve injury related to the use of a self retaining retractor for internal mammary artery dissection. J Cardiovasc Surg (Torino) 1989;30:1015-16.

17 Hallikainen H, Partanen J, Mervaala E. The importance of neurophysiological evaluation of plexus brachialis injury caused by open heart surgery. Electromyogr Clin Neurophysiol 1993;33:67-71.

18 Lin PY, Luo CY, Kan CD, et al. Brachial plexus injury following coronary artery bypass surgery: a case report. Kaohsiung J Med Sci 2000;16:638-42

19 Martin MA, Mari C, Miranda AF, et al. [Pain caused by brachial plexus injury during coronary revascularization. Report of 3 cases.] Rev Esp Anestesiol Reanim 1992;39:180-2

20 Lederman RJ, Brever AC, Hanson MR, et al. Peripheral nervous system complications of coronary artery bypass graft surgery. Ann Neurol 1982;12:297-301

21 Hickey C, Gugino LD, Aglio LS, et al. Intraoperative somatosensory evoked potential monitoring predicts peripheral nerve injury during cardiac surgery. Anesthesiology 1993;78:29-35.

22 Jellish WS, Martucci J, Blakeman B, et al. Somatosensory evoked potential monitoring of the brachial plexus to predict nerve injury during internal mammary artery harvest: intraoperative comparisons of the Rultract and Pittman sternal retractors. J Cardiothorac Vasc Anesth 1994; 8:398-403.

23 Baisden CE, Greenwald LV, Symbas PN. Occult rib fractures and brachial plexus injury following median sternotomy for open-heart operations. Ann Thorac Surg 1984;38:192-4.

24 Duhaylongsod FG, Mayfield WR, Wolf RK. Thoracoscopic harvest of the internal thoracic artery: a multicenter experience in 218 cases. Ann Thorac Surg 1998;66:1012-17.

25 Nataf $\mathbf{P}$, Al Attar N, Ramadan R, et al. Thoracoscopic IMA takedown. J Card Surg 2000; 15:278-82

26 Watanabe G, Misaki T, Kotoh K, et al. Bilateral thoracoscopic minimally invasive direct coronary artery bypass grafting using internal thoracic arteries. Ann Thorac Surg 1998;65:1673-5.

27 Nataf $\mathbf{P}$, Lima $L$, Regan $M$, et al. Thoracoscopic internal mammary artery harvesting: technical considerations. Ann Thorac Surg 1997;63/6 suppl):S104-6

28 Nataf $\mathbf{P}$, Lima $L$, Regan $M$, et al. Minimally invasive coronary surgery with thoracoscopic internal mammary artery dissection: surgical technique. J Card Surg 1996;11:288-92.

29 Jellish WS, Blakeman $B$, Warf $P$, et al. Hands-up positioning during asymmetric sternal retraction for internal mammary artery harvest: a possible method to reduce brachial plexus injury. Anesth Analg 1997:84:260-5.

30 Swenson JD, Bull DA. Postoperative ulnar neuropathy associated with prolonged ischemia in the upper extremity during coronary artery bypass surgery. Anesth Analg 1997;85:1275-7.

31 Miller RG, Camp PE. Postoperative ulnar neuropathy. JAMA 1979;242: 1636-9

32 Eggers KA, Asai T. Postoperative brachial plexus neuropathy after total knee replacement under spinal anaesthesia. $\mathrm{Br} J$ Anaesth 1995;75:642-4.

33 Warner MA, Warner ME, Martin JT. Ulnar neuropathy. Incidence, outcome, and risk factors in sedated or anesthetized patients. Anesthesiology 1994;81:1332-40.

34 Miller RG, Camp PE. Postoperative ulnar neuropathy. JAMA 1979;242:1636-9

35 Tomlinson DL, Hirsch IA, Kodali SV, et al. Protecting the brachial plexus during median sternotomy. J Thorac Cardiovasc Surg 1987;94:297301 . 